\title{
MOST RELIABLE PARAMETER OF THE MANDIBLE USED FOR SEX
} DETERMINATION

\author{
Babita Kujur ${ }^{1}$, Naina S. Wakode ${ }^{* 2}$, Manisha R. Gaikwad ${ }^{3}$, Santosh L. Wakode ${ }^{4}$. \\ ${ }^{1}$ Senior resident, Department of Anatomy, AlIMS, Bhubaneswar, India. \\ ${ }^{*}$ Associate Professor, Department of Anatomy, AlIMS, Bhubaneswar, India. \\ ${ }^{3}$ Additional Professor \& Head, Department of Anatomy, AlIMS, Bhubaneswar, India. \\ ${ }^{4}$ Associate Professor, Department of Physiology, AlIMS, Bhopal, India.
}

\section{ABSTRACT}

Background: The determination of sex from human skeletal material is of fundamental importance for any forensic investigator. Sexual dimorphism refers to the differences in size, stature, and appearance between male and female. The mandible is considered suitable for study as it is the most durable bone of the face and has got sexual dimorphism. So the present study was done to determine the usefulness of mandible as an aid in sex determination.

Materials and methods: The present study was done on 47 mandibles ( 22 males and 25 females) from department of anatomy, all india institute of medical sciences, bhubaneswar, to find out the most reliable metric parameter in mandible to determine the sex of an unidentified individual.

Results: In our study we found that the angle of the mandible, bigonial breadth and bicondylar breadth were the most reliable parameters. The mean value of angle of the mandible, bigonial and bicondylar breadth in male was $126.73 \pm 2.71,94.69 \pm 2.46,111.20 \pm 5.73 \mathrm{~mm}$ respectively and in female $135.42 \pm 2.58,88.27 \pm 7.84,107.89 \pm 4.03 \mathrm{~mm}$ with $\mathrm{p}$ value $0.0001,0.0006$ and 0.0287 respectively.

Conclusion: This study may help in identifying the sex of mutilated and unidentified bodies when combined with some other criteria used for sex determination.

KEYWORDS: Angle of mandible, Bigonial breadth, Bicondylar breadth, Sexual dimorphism.

Address for Correspondence: Dr. Naina S. Wakode, Associate Professor, Department of Anatomy, AlIMS, Bhubaneswar, India. E-Mail: nainawakode@gmail.com

\begin{tabular}{|c|c|c|}
\hline \multicolumn{3}{|c|}{ Access this Article online } \\
\hline \multirow{2}{*}{$\begin{array}{l}\text { Quick Response code } \\
\text { DOI: } 10.16965 / \text { ijar.2017.419 }\end{array}$} & \multicolumn{2}{|c|}{$\begin{array}{l}\text { Web site: International Journal of Anatomy and Research } \\
\qquad \text { ISSN 2321-4287 } \\
\text { www.ijmhr.org/ijar.htm }\end{array}$} \\
\hline & $\begin{array}{l}\text { Received: } 15 \text { Aug } 2017 \\
\text { Peer Review: } 16 \text { Aug } 2017 \\
\text { Revised: None }\end{array}$ & $\begin{array}{l}\text { Accepted: } 03 \text { Oct } 2017 \\
\text { Published (O): } 01 \text { Nov } 2017 \\
\text { Published (P): } 01 \text { Nov } 2017\end{array}$ \\
\hline
\end{tabular}

\section{INTRODUCTION}

Sexual dimorphism in the mandible may be due to the relative difference in the development of the musculoskeletal system, especially the muscles of mastication attached to the mandible [1]. In the adult skeleton, sex determination is usually the first step of the identification process, as subsequent methods for age and stature estimation are sex dependent. Depend- ability of sex determination relies on the completeness of the remains and the degree of sexual dimorphism inherent in a population, but it is usually considered that the two most sexually dimorphic elements of the skeleton are the skull (including the mandible) and the pelvis. The need for such a type of research is due to the increased incidents of violence and the increased number of unidentified and muti- 
lated bodies being referred to the forensic expert [2]. If different parameters are tested within specific population groups, both qualitative and quantitative criteria can be identified and used in combination to distinguish sex, age and ethnicity [3]. Various studies have clearly indicated that the skeletal characters vary by population, and there is a need to lay down population-specific standards [4]. The mandible is the largest and strongest bone in the face with a horizontally curved body that is convex forwards with two broad rami, which ascend from the posterior end of the body. The rami bears the coronoid and condyloid processes [5]. The mandible is considered suitable for study as it is the most durable bone of the facial skeleton and retains its shape better than other bones. Sexual dimorphism in the mandible may be due to the relative difference in the development of the musculoskeletal system, especially the muscles of mastication attached to the mandible [1]. The knowledge about the anatomy of the mandible and its variations in age, sex and race will help physicians, surgeons, medico-legal authorities and anthropologists to give correct interpretations for the diagnostic procedures in living. So the present study was done with the aim to find out the most reliable parameter of the mandible in determination of the sex of an individual.

\section{MATERIALS AND METHODS}

The present study was done on $\mathbf{4 7}$ mandibles, obtained from department of anatomy, all India institute of medical Sciences, bhubaneswar. The mandibles were categorized into male and female on the basis of morphological features. The bones collected were free from any pathological lesions or fractures. Totally edentulous mandibles with absorbed alveolar margins were excluded from this study. The following parameters were taken:

1. Gonial evertion

2. Shape of the chin.

3. Lateral aspect of the angle.

4. Mandibular ramus flexure

5. Angle of the mandible (Angle)

6. Diagonal length of the mandible body (DL)

7. Horizontal length of the mandibular body or Mandibular length ( $\mathrm{HL})$

8. Bigonial breadth (BGB)
9. Bicondylar breadth (BCB)

10 Mandibular ramus breadth (MRB)

11. Mandibular index (MI) =

Mandibular length x100

Bicondylar breadth

All the parameters were taken with the help of digital Vernier callipers with an accuracy of $0.01 \mathrm{~mm}$, protractor and scale .The measurements were taken on the right side of the mandible. The data were recorded in Microsoft excel sheet and the mean and the standard deviation were derived.

Angle of the mandible: It was the angle between the base and a tangent drawn along the posterior border of the ramus, touching the posterior-most point on the condyle and the posterior-most point on the posterior border, taken with the help of a protractor.

Diagonal length of the mandible body: The DL of the mandibular body was measured from the point at the base of the mandible at the level of the symphysis menti to the posterior-most point at the angle at the junction of the body and the ascending rami of the mandible with the help of digital Vernier callipers (Fig 1).

Horizontal length: The distance between two horizontal lines between the two bony points (symphysis menti and mid-point of two angles of the mandible).

Bigonial breadth: The linear distance between two mandibular angles (Fig no. 2.) taken with the help of digital Vernier calliper.

Bicondylar breadth: The linear distance between lateral most points of the two condyles of the mandible (Fig. 3).

Mandibular ramus breadth: Minimum anteroposterior breadth of the ramus (right side) was measured with the help of digital Vernier callipers (Fig. 4).

\section{RESULTS}

Out of 47 mandibles, 22 were male and 25 were female. The parametric data were recorded and the mean, standard deviation and $p$ value were derived.

Statistical Analysis: The values were analysed by unpaired student $t$ - test using SPSS software (version 17.01). $\mathrm{p}$ value $\leq 0.05$ was considered statistically significant (Table 1 ). 
Table 1: Showing mean, standard deviation and $p$ value

of different parameters

measured in the mandible.

$\{$ Significant value - marked $*$ \}

\begin{tabular}{|c|c|c|c|c|c|c|}
\hline \multirow{2}{*}{ S.no. } & \multirow{2}{*}{ Parameters } & \multicolumn{2}{|c|}{ Male( $\mathrm{n}=\mathbf{2 2})$} & \multicolumn{2}{c|}{ Female( $\mathrm{n}=\mathbf{2 5})$} & \multirow{2}{*}{ p value } \\
\cline { 3 - 6 } & & Mean & SD & Mean & SD & \\
\hline $\mathbf{1}$ & Angle of mandible & 126.73 & 2.71 & 135.42 & 2.58 & $0.0001^{*}$ \\
\hline $\mathbf{2}$ & Diagonal length & 82.84 & 4.23 & 80.92 & 4.09 & 0.121 \\
\hline $\mathbf{3}$ & Horizontal length & 72.91 & 5.39 & 71.53 & 5.24 & 0.3788 \\
\hline $\mathbf{4}$ & Bigonial breadth & 94.69 & 2.46 & 88.27 & 7.84 & $0.0006^{*}$ \\
\hline $\mathbf{5}$ & Bicondylar breadth & 111.2 & 5.73 & 107.89 & 4.03 & $0.0287^{*}$ \\
\hline $\mathbf{6}$ & Mandibular ramus Breadth & 31.43 & 3.33 & 30.11 & 2.33 & 0.1273 \\
\hline $\mathbf{7}$ & Mandibular index & 65.49 & 4.81 & 64.44 & 5.2 & 0.4781 \\
\hline
\end{tabular}

Table 2: Comparisons of various parameters (in millimetres) of the male mandible.

\begin{tabular}{|c|c|c|c|c|c|c|c|c|}
\hline \multirow{2}{*}{ Sr. no } & \multirow{2}{*}{ Authors } & \multicolumn{2}{|c|}{ Parameters } \\
\cline { 3 - 9 } & Present study & Angle & DL & HL & BGB & BCB & MRB & MI \\
\hline 1 & Anupam Datta et al [8] & $126.73 \pm 2.71$ & $82.84 \pm 4.23$ & $72.91 \pm 5.39$ & $94.69 \pm 2.46$ & $111.20 \pm 5.73$ & $31.43 \pm 3.33$ & $65.49 \pm 4.81$ \\
\hline 2 & Maneesha Sharma et al [11] & $124 \pm 6.27$ & $79.77 \pm 4.68$ & $71.99 \pm 4.54$ & - & - & $30.92 \pm 2.55$ & - \\
\hline 3 & Vinay G et al [13] & - & - & - & $94.5 \pm 5.3$ & $113.4 \pm 5.5$ & - & $66.52 \pm 4.42$ \\
\hline 4 & Jayakaran etal [14] & - & - & - & $93.8 \pm 5.4$ & $112.6 \pm 5.3$ & - & - \\
\hline 5 & Ranganath et al [15] & - & - & - & $86.8 \pm 13.7$ & $109.8 \pm 14.8$ & - & - \\
\hline 6 & Franklin et al [2] & - & - & - & $93.5 \pm 5.7$ & $113.6 \pm 6.0$ & - & - \\
\hline 7 & Ongkana N et al [1] & - & $8.32 \pm 0.52$ & - & $96.8 \pm 7.7$ & $123.8 \pm 6.3$ & - & - \\
\hline 8 & Mitra Akhlaghi et al [10] & $113.20 \pm 7.91$ & - & - & $74.9 \pm 4.3$ & - & $33.6 \pm 4.7$ & - \\
\hline 9 & Noha Saleh Abu Taleb et al [7] & $122.2 \pm 4.8$ & - & - & - & - & - & - \\
\hline 10 & - & - & - & - & - & $33.02 \pm 2.80$ & - \\
\hline 11 & Bhagwatkar Tet al [17] & - & - & & - & - \\
\hline
\end{tabular}

Table 3: Comparisons of various parameters (in millimetres) of the female mandible.

\begin{tabular}{|c|c|c|c|c|c|c|c|c|}
\hline \multirow{2}{*}{ Sr. no } & \multirow{2}{*}{ Authors } & \multicolumn{9}{|c|}{ Parameters } \\
\cline { 3 - 9 } & & Angle & DL & HL & BGB & BCB & MRB & MI \\
\hline 1 & Present study & $135.42 \pm 2.58$ & $80.92 \pm 4.09$ & $71.53 \pm 5.24$ & $88.27 \pm 7.84$ & $107.89 \pm 4.03$ & $30.11 \pm 2.33$ & $64.44 \pm 5.20$ \\
\hline 2 & Anupam Datta et al [8] & $135.72 \pm 8$ & & $70.64 \pm 4.77$ & $88.75 \pm 6.78$ & $107.48 \pm 7.68$ & - & $58.12 \pm 4.86$ \\
\hline 3 & Maneesha Sharma et al [11] & $124.03 \pm 5.3$ & $73.83 \pm 4.84$ & $68.62 \pm 4.78$ & - & - & $29.56 \pm 2.86$ & - \\
\hline 4 & Vinay G et al [13] & - & - & - & $87.4 \pm 0.54$ & $108.2 \pm 0.70$ & - & $66.41 \pm 5.69$ \\
\hline 5 & Jayakaran et al [14] & - & - & - & $87.1 \pm 0.48$ & $107.7 \pm 0.53$ & - & - \\
\hline 6 & Ranganath et al [15] & - & - & - & $86.2 \pm 0.72$ & $115.1 \pm 0.93$ & - & - \\
\hline 7 & Franklin et al [2] & - & - & - & $87.0 \pm 0.56$ & $108.6 \pm 0.58$ & - & - \\
\hline 8 & Ongkana N et al [1] & - & - & - & $89.7 \pm 0.59$ & $116.1 \pm 0.59$ & - & - \\
\hline 9 & Mitra Akhlaghi et al [10] & $100.60 \pm 12.02$ & - & - & $85.2 \pm 7.0$ & - & $30.3 \pm 4.0$ & - \\
\hline 10 & Noha Saleh Abu Taleb et al [7] & $125.1 \pm 4.3$ & - & - & - & - & - & - \\
\hline 11 & Bhagwatkar T et al [17] & - & - & - & - & - & $31.57 \pm 2.43$ & - \\
\hline
\end{tabular}

Fig. 1: Showing measurement of diagonal length.

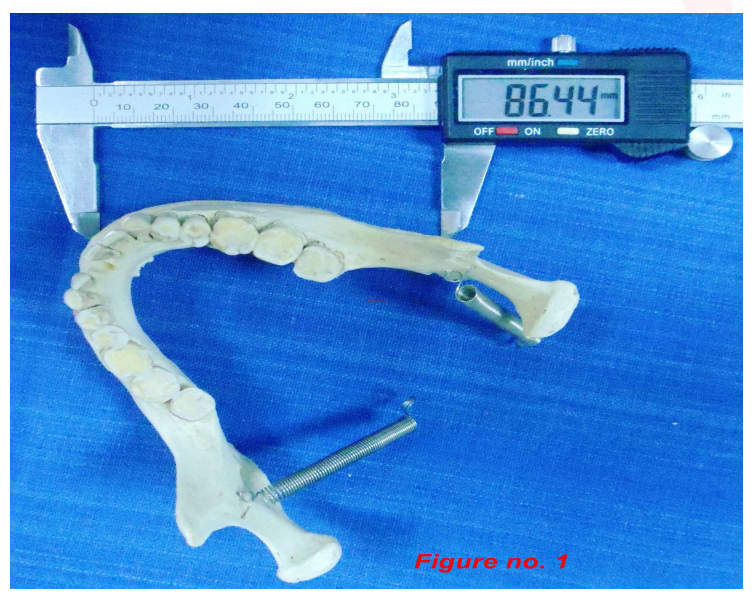

Fig. 2: Showing measurement of bigonial breadth.

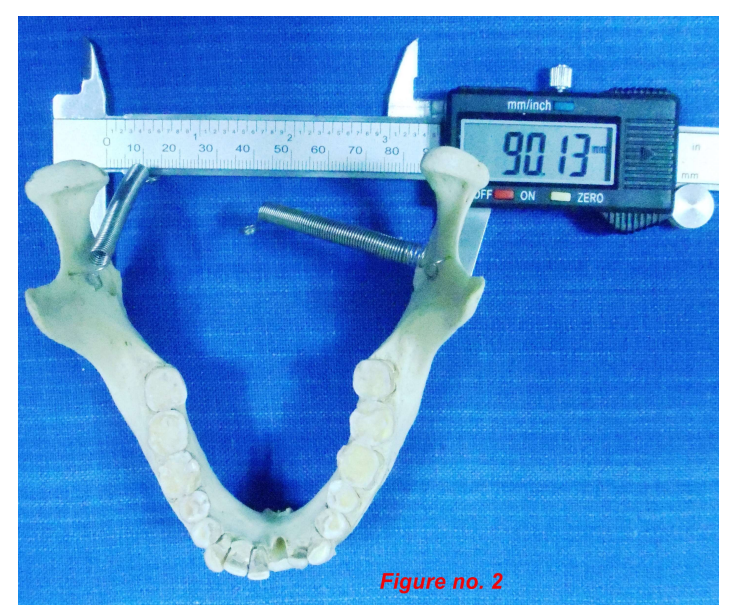


Fig. 3: Showing measurement of bicondylar breadth.

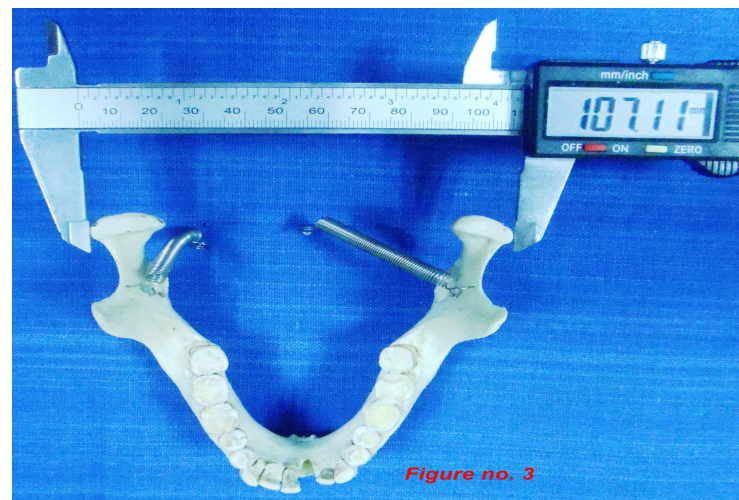

Fig. 4: Showing measurement of mandibular ramus breadth.

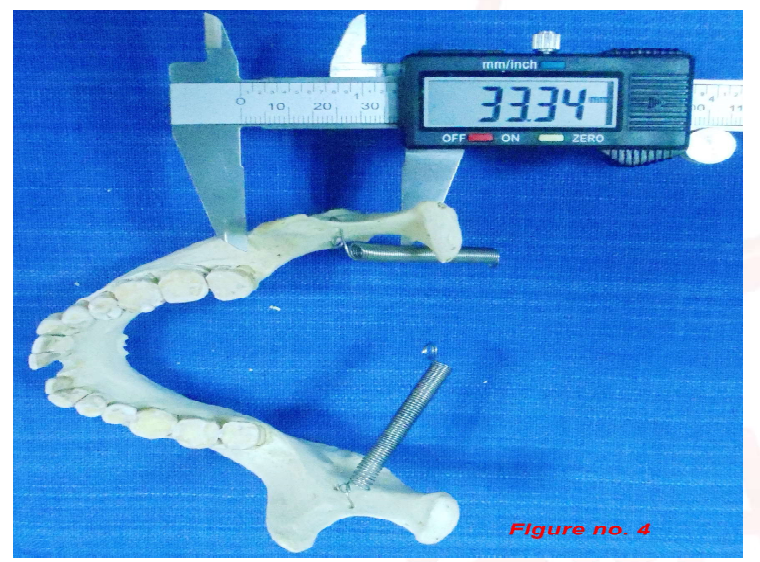

\section{DISCUSSION}

Determination of sex is a very important part of study in anthropology and forensic science, as further investigations will be based on it [6]. Mandibles can be used for sexual dimorphism as it is readily available and resistant to any disintegration process. However, levels of sexual dimorphism are population specific due to a combination of genetic and environmental factors. In our study, we measured 6 parameters of the mandible, out of which three variables showed statistically significant difference between both sexes. This shows that mandible expresses strong sexual dimorphism.

Angle of Mandible: In the present study mean mandibular angle in female was greater than male (table no.1), which when subjected to statistical analysis, the p-value was found to be lesser than 0.05 (0.0001), making this difference highly signiûcant (Table 1 ). This was in agreement with many researchers $[7,8]$. Conversely, other researchers found that males showed statistically significant higher mean gonial angle values than females [9], and others did not find any statistically significant differences between both sexes $[10,11,12]$. It was found that females had a downward and backward rotation in mandible while males had a forward rotation in mandible [12]. Hence the gonial angle in females is higher than in males.

Diagonal length (DL): The mean value of the diagonal length in male was greater than female but the $p$ value was found to be greater than 0.05 (Table 1) Compared with Ongkana $\mathrm{N}$ et al [1] and Maneesha Sharma et al [11] who found that the males have significantly greater diagonal length than the females.

Horizontal length (HL): Previous studies done by Anupam Datta et al [8], Maneesha Sharma et al [11] and Vinay G et al [13] found that the horizontal length of the mandible was significantly greater in males than in females (Table no.2 and 3). In the present study also the horizontal length in male was greater than female but on further analysis it was found to be statistically insignificant with $p$ value $>0.05$ (Table 1 ).

Bigonial breadth (BGB): The bigonial breadth of the mandible was significantly greater in male than in female having $p$ value 0.0006 (Table no.1). This was in agreement with other researchers like Anupam Datta et al ( $p=0.0001)$ [8], Mitra et al $(p=0.001)[10]$, Vinay $G$ et al $(p=0.0001)$ [13], Jayakaran et al. [14], Ranganath et al. [15] and Ongkana $\mathrm{N}$ et al [1] (Table no. 2 and 3)

Bicondylar breadth (BCB): Studies conducted by Ongkana et al [1], Anupam Datta et al [8], Vinay $G$ et al [13], Jayakaran et al. [14], Ranganath et al. [15] and Franklin et al. [16] showed statistically significant difference between male and female mandibular values. (Table no. 2 and 3) The mean value of bicondylar breadth of mandibles in the present study was almost similar to previous studies having $p$ value 0.0287(Table 1)

\section{Mandibular ramus Breadth (MRB):}

In the present study, mandibular ramus breadth in male was greater than female. But when these values of mandibular ramus breadth were subjected to further analysis, $p$ value $>0.05$ (Table 1) making it insignificant for sex determination. Study conducted by Mitra Akhlaghi et al [10] found similar result. But Maneesha Sharma et al [11] and Tejashree Bhagwatkar et al [17]found significant difference between male and female having $p$ value 0.01 and 0.026 
respectively.(Table no.2 and 3)

Mandibular Index (MI): The mandibular index showed insignificant difference between male and female ( $p$ value $>0.05$ ) (Table 1$)$. This was in same line with Anupam Datta [8] and Vinay G et al [13] having $p$ value 0.929 and 0.88 respectively.(Table 2 and 3 )

The differences observed in male and female mandibles may be explained on the basis of genetically determined factors, like the size of teeth, and local factors, like muscle forces (weaker in females as compared with males). Sexual division of labour and access to adequate nutrition are the other factors responsible for sexual dimorphism of bones [18]. In the present study mean values of angle of the mandible, bigonial breadth and bicondylar breadth was observed to be significantly higher with a $p$-value less than 0.05. This indicates that these features are sexually dimorphic and hence can be used for sexing the mandible.

\section{CONCLUSION}

From the present study, it can be concluded that morphological criteria are observable and need enough experience but metric parameters of the mandible like angle of the mandible, bigonial breadth and bicondylar breadth can be used in identifying the sex of mutilated and unidentiûed bodies when combined with some other criteria used for sex determination. According to our study the angle of the mandible, bigonial breadth and bicondylar breadth are found to be most reliable parameters of mandible for sex determination. As our sample size was smaller, so further study is required with larger sample size to standardize these parameters for sex determination.

\section{Conflicts of Interests: None}

\section{REFERENCES}

[1]. Ongkana N, Sudwan P. Gender difference in Thai mandibles using metric analysis. Chiang Mai Med J 2009; 48(2):43-8.

[2]. D. Franklin, O.P. Higgins, C.E. Oxnard Sexual dimorphism in the mandible of indigenous South Africans: a geometric morphometric approach S Afr J Sci, 2008;104(3):101-109.

[3]. F.M. Fabian, R.M pembeni Sexual dimorphism in the mandibles of a homogenous black population of Tanzania Tan J Sci, 2002;28(2):4753.
[4]. M. Vodanovic, J. Dumancic, Z. Demo, D. Mihelic Determination of sex by discriminant function analysis of mandibles from two Croatian archeological sitesActa Stomatol Croat, 2006;40(3):263-277.

[5]. Susan Standring Gray's Anatomy: the anatomical basis of clinical practice, 40th ed., London Churchill Livingstone Elsevier 2008, pp 530-532.

[6]. Rai R, Ranade AV, Prabhu LV, Pai MM, Madhyastha S,Kumaran M. A pilot study of the mandibular angle and ramus in Indian population. Int J Morphol 2007;25(2):353-6.

[7]. Noha Saleh Abu-Taleb and Dina Mohamed EI Beshlawy Mandibular Ramus and Gonial Angle Measurements as Predictors of Sex and Age in an Egyptian Population Sample: A Digital Panoramic Study. J Forensic Res 2015;6:5.

[8]. Anupam Datta, Santhosh Chandrappa Siddappa, Viswanathan Karibasappa Gowda, Siddesh Revapla Channabasappa, Satish BabBanagere Shivalin gappa, Srijith, Debaleena Dey; A Study of Sex Determination from Human Mandible Using Various Morphometrical Parameters. Indian Journal of Forensic and Community Medicine, July - September 2015;2(3):158-166.

[9]. Kharoshah MA, Almadani O, Ghaleb SS, Zaki MK, Fattah YA. Sexual dimorphism of the mandible in a modern Egyptian population. J Forensic Leg Med 2010;17:213-215

[10]. Akhlaghi M, Khalighi Z, Vasigh S, Yousefinejad V. Sex determination using mandibular anthropometric parameters in subadult Iranian samples. J Forensic Leg Med 2014;22:150-3.

[11]. Maneesha Sharma, R.K. Gorea, Arshdeep Gorea and Abdulwahab Abuderman. A morphometric study of the human mandible in the Indian population for sex determination; Egyptian Journal of Forensic Sciences 2016;6:165-169.

[12]. Pecora NG, Baccetti T, McNamara JA Jr The aging craniofacial complex: a longitudinal cephalometric study from late adolescence to late adulthood. Am J Orthod Dentofacial Orthop 2008;134:496-505.

[13]. Vinay G, Gowri M, Anbalagan J. Sex determination of human mandible using metrical parameters. J Clin Diagnostic Res 2013;7(12):2671-2673.

[14]. Flossie Jayakaran, Sayee Rajangam, Janakiram S, Thomas IM. Sexing of the mandible. Anatomica Karnataka. 2000;1(1):11-16.

[15]. Ranganath Vallabhajosyula, Yogitha Ravindranath, Roopa Ravindranath. Sexual dimorphism in mandibular morphology: a study on South Indian sample. South Asian Anthropologist 2008;8(1):9-11.

[16]. Daniel Franklin, Paul O'Higgins, Charles E Oxnard, Ian Dadour. Sexual dimorphism in the subadult mandible:quantification using geometric morphometrics. J Forensic Sci. 2007;52(1):6-10.

[17]. Tejashree Bhagwatkar, Manjiri Thakur, Devendra Palve, Apoorva Bhondey,Yogita Dhengar, SwatiChaturvedi; Sex determination by using mandibular ramus - A forensic study. Journal of Advanced Medical and Dental Sciences Research 2016;4(2):1-6

[18]. Frayer DW, Wolpoff MH.Sexual dimorphism. Ann RevAnthropol 1985; 14:429-73.

How to cite this article: Babita Kujur, Naina S. Wakode, Manisha R. Gaikwad, Santosh L. Wakode. MOST RELIABLE PARAMETER OF THE MANDIBLE USED FOR SEX DETERMINATION. Int J Anat Res 2017;5(4.2):4611-4615. DOI: 10.16965/ijar.2017.419 